\title{
ESTIMATION OF GENETIC PARAMETERS FOR GROWTH TRAITS USING DIFFERENT MODELS FOR FRIESIAN CATTLE RAISED IN EGYPT
}

\author{
Safaa S. Sanad and M.G.Gharib
}

\author{
Animal Production Research Institute, Agriculture Research Center, Ministry of Agriculture, Egypt \\ SUMMARY
}

This study was conducted to detect the most appropriate model that fits data of birth weight (BW) and weaning weight $(W W)$ traits of Friesian calves. Body weights of 1371 calves over a 22 years and WW of 678 Friesian calves over a 19 years from a herd of Friesian in Gemmaza Ministry of Agriculture, Egypt were used. The fixed effects included in the model were parity, season, sex, year of calving in addition to the random effects to estimate direct and maternal heritability's, permanent maternal environmental and error. The parameters were estimated by using Variance Component Estimation (MTDFREML) programs. Six different animal models were fitted for the traits ranging from a simple to the most comprehensive model, were used to compare them.

The overall means were $30.4 \mathrm{~kg}$ and $85.1 \mathrm{Kg}$, for $\mathrm{BW}$ and $W W$, respectively. Non-genetic factors (fixed effects) had highly significant $(P<0.001)$ effects on $B W$ and $W W$ of calves. Estimates of direct heritability were moderate, they ranged from 0.28 to 0.30 for $B W$ and from 0.18 to 0.28 for $W W$. Maternal heritability was relatively low for both $B W$ and $W W$, ranging from 0.06 to 0.08 for $B W$ and was 0.04 for $W W$. Permanent environmental effect $P e^{2}$ in the $2^{\text {nd }}$ model was relatively higher than that of other models, while inclusion of maternal genetic effects (Models 3-6) showed further reduction in $h^{2}{ }_{a}$ for which there was negligible difference in $h^{2}$ of the other models within each trait.

Akaike Information Criterion (AIC) was used to determine the most appropriate model for the studied traits. Model $5: Y=X b+Z 1 a+Z 2 c+Z 3 m+e \operatorname{Cov}(a, m)=0 A \sigma$ am was the most appropriate model for BW, while, Model 4 : $Y=X b+Z 1 a+Z 3 m+e \operatorname{Cov}(a, m)=A \sigma$ am was the most appropriate model for $W W$ trait.

The higher range of calves breeding values compared with those of sire or dams means that selection for $B W$ for calves is leading to an increase in WW for the next generation.

Keywords: Birth and weaning weight, Friesian calves, genetic and non-genetic parameters, models Comparisons

\section{INTRODUCTION}

Animal models utilize all relationships available in a given data set. The search for a suitable statistical model is an important step in the development of genetic improvement (Assan et al.,2011).Genetic models, including maternal effects and the covariance of direct and maternal genetic effects, fit data better than the simple additive model (Martinez et al.,2016); for maternal traits such as weight in early ages. Animal models used to analyze post weaning growth traits in beef cattle typically may not assume maternal effects. Genetic and phenotypic parameters in quantitative genetics include heritability, genetic and phenotypic correlations, which play a vital role in the formulation of any suitable breeding plan for genetic improvement program (Aynalem,2006). Growth traits in cattle are important in selection program. So that, estimating the genetic parameters for estimation of variance and covariance components (Sadek et al.,2005)as well as growth traits and implementing them in a selection program would be of great value, for beef breeds for the purpose of fattening small calves.

The objectives of the present work were to compare estimates of genetic parameters for Friesian cattle birth weight (BW) and weaning weight (WW) using different statistical models to determine whether simpler models produce estimates similar to those produced by more complex alternatives.

\section{MATERIALS AND METHODS}

Data used in the present study were collected from the history sheets of Friesian cows maintained at Gamaza farm belonging to Animal Production Research Institute (APRI), Ministry of Agriculture, Egypt. Herd size is shown in Table1. This data were used for assessment of genetic parameters that affect growth traits of Friesian cattle in dairy herds.

Table1. Structure of data used in the study

\begin{tabular}{lcc}
\hline Structure of data & BW & WW \\
\hline Number of calves & 1371 & 678 \\
Sire & 79 & 59 \\
Dams & 432 & 285 \\
Environmental effects & & 19 \\
Year & 22 & 4 \\
Calving season & 4 & 8 \\
Calving number & 8 & 2 \\
Calf sex & 2 & \\
\hline
\end{tabular}

Issued by The Egyptian Society of Animal Production 
It is noted that the number of calves born is more than the number of calves weaned which may be due to the management of herd, registration systems and the presence of some of the losses of calves born before reaching weaning stage.

\section{Herd management:}

Animal nutrition in the experimental farm depends on concentrate feed mixture along with wheat or rice straw in addition to Egyptian clover in winter or clover hay during summer (May to November). As a common practice, milking cows were subjected to machine milking twice daily.

Calves were produced mainly by artificial insemination (imported frozen semen of Friesian sires) rather than by natural service mating. After calving, birth weight, sex and pedigree were recorded. Calves were allowed to receive the colostrums, from their dams for the first four days. Colostrum was offered three times daily totaling $10 \%$ of the calf's body weight. From the fifths day of age, calves were fed on natural whole milk and then milk, starter and hay Natural whole milk, starter and hay were offered based on the weight of the calve. The starter (18\% protein) was formulated as follows: Maize (54\%), soybean (25\%), wheat bran (15\%), limestone $(2 \%)$, ordinary salt $(1 \%)$ and molasses $(3 \%)$. Water was available all the time except one hour before every time of feeding on milk. Feeding program was essentially that applied in the experimental farm under consideration. Friesian calves were used to evaluate the growth performance of Friesian calves from birth to 90 days of age as a weaning weight of Friesian calves after weaning were evaluated.

Besides all herd had regular veterinary consultants for disease management control and vaccination.

\section{Statistical analysis:}

Data was analyzed using the general linear model (GLM) procedure (SAS 2003).

The following statistical mixed model was used:

$\mathrm{Y}_{\mathrm{ijklm}}=\mu+\mathrm{S}_{\mathrm{i}}+\mathrm{P}_{\mathrm{j}}+\mathrm{SE}_{\mathrm{k}}+\mathrm{YE}_{\mathrm{l}}+\mathrm{X}_{\mathrm{n}}+(\mathrm{YE} * \mathrm{SE})_{\mathrm{lk}}+\mathrm{e}_{\mathrm{ijklnm}}$ where,

$\mathrm{Y}_{\mathrm{ijklm}}$ : either (BW)or (WW)

$\mu$ : an underlying constant specific to each trait;

$i^{\text {th }}$ sire(random effect);

$P_{j}$ : the fixed effect of $j^{\text {th }}$ parity of calving;

$\mathrm{SE}_{\mathrm{k}}$ : the fixed effect of $\mathrm{k}^{\text {th }}$ season of calving; $\mathrm{YE}_{\mathrm{l}}$ : the fixed effect of $\mathrm{l}^{\text {th }}$ year of calving, $\mathrm{X}_{\mathrm{n}}$ sex of calf; $(\mathrm{YE} * \mathrm{SE})_{\mathrm{lk}}$ the interaction between $1^{\text {th }}$ effect of year of calving and $\mathrm{K}^{\text {th }}$ effect of season of calving and $\mathrm{e}_{\mathrm{ijk} k \mathrm{n}}$ :random residual assumed to be independent normally distributed with mean zero and variance $\sigma^{2}$ e.

Variance and covariance components were estimated with derivative-free restricted maximum likely hood (REML) procedures using the MTDFREML program according to Boldman et al.(1995), six animal models were fitted examined for each trait.

The following models were used:

Model 1: $\mathbf{Y}=\mathbf{X b}+\mathbf{Z}_{\mathbf{1}} \mathbf{a}+\mathbf{e}(1)$

Model 2: $\mathbf{Y}=\mathbf{X b}+\mathbf{Z}_{\mathbf{1}} \mathbf{a}+\mathbf{Z}_{\mathbf{2}} \mathbf{c}+\mathbf{e}(2)$

Model 3:Y=Xb+Z $\mathbf{Z} \mathbf{a}+\mathbf{Z}_{3} \mathbf{m}+\mathbf{e}, \mathbf{C o v}(\mathbf{a}, \mathbf{m})=\mathbf{0 A} \boldsymbol{\sigma}_{\mathbf{a m}}(3)$

Model 4:Y=Xb+Z $\mathbf{Z}_{\mathbf{1}} \mathbf{a}+\mathbf{Z}_{\mathbf{3}} \mathbf{m}+\mathbf{e}, \mathbf{C o v}(\mathbf{a}, \mathbf{m})=\mathbf{A} \boldsymbol{\sigma}_{\mathbf{a}, \mathbf{m}}$ (4)

Model 5:Y=Xb+Z $\mathbf{Z}_{1} \mathbf{a}+\mathbf{Z}_{2} \mathbf{c}+\mathbf{Z}_{3} \mathbf{m}+\mathbf{e}, \operatorname{Cov}(\mathbf{a}, \mathbf{m})=\mathbf{0} \mathbf{A} \sigma_{\mathbf{a m}}$ (5)

Model $6: \mathbf{Y}=\mathbf{X b}+\mathbf{Z}_{1} \mathbf{a}+\mathbf{Z}_{2} \mathbf{c}+\mathbf{Z}_{3} \mathbf{m}+\mathbf{e ,} \operatorname{Cov}(\mathbf{a}, \mathbf{m})=\mathbf{A}$ $\sigma_{\mathrm{a}, \mathrm{m}}(6)$

Where $\mathrm{Y}$ is the vector of observations while $\mathbf{b}, \mathbf{a}$, $\mathbf{m}, \mathbf{c}$ and eare the vectors of fixed effects, direct additive genetic affects, maternal genetic effects, permanent environmental, maternal effect and the residual effect, respectively. $\mathrm{X}, \mathrm{Z}_{\mathrm{a}}, \mathrm{Z}_{\mathrm{m}}$, and $\mathrm{Z}_{\mathrm{c}}$, are the matrices of fixed effects, direct additive genetic effects, maternal genetic effects and permanent environmental effect of dam, respectively. A is the numerator additive genetic relationship matrix between animals and $\operatorname{Cov}(\mathrm{a}, \mathrm{m})=\mathrm{A} \sigma_{\mathrm{a}, \mathrm{m}}$ where $\sigma_{\mathrm{a}, \mathrm{m}}$ is the covariance between direct and maternal genetic effects, $\sigma_{a}^{2}$ the direct additive genetic variance, $\sigma_{m}^{2}$ the maternal genetic variance, $\sigma^{2}$ che variance of the permanent environmental effect of the dam and $\sigma_{\mathrm{e}}^{2}$ the variance of the residuals. Depending on the model the log likelihood function was maximized with respect to direct heritability $\left(\mathrm{h}^{2}{ }_{\mathrm{a}}\right)$, maternal heritability $\left(\mathrm{h}_{\mathrm{m}}^{2}\right)$, permanent environmental variance of the dam as a proportion of the phenotypic variance $\left(c^{2}\right)$, and the genetic effects as a proportion of the total variance $\left(\mathrm{c}_{\mathrm{am}}\right)$.

Log-likelihood ratio tests (LRT) were used to determine the most appropriate model by comparing the differences between log-likelihoods (-2Log L) to a critical value from a chi-square distribution. Using LRT, the Akaike information criterion (AIC) of Akaike (1973) was computed to rank the models. Letp denote the number of random (co) variance parameters to be estimated and $-2 \log \mathrm{L}$ is the maximum likelihood. Then the Akaike information criterion is defined as: $\mathrm{AIC}=-2 \log \mathrm{L}+2 \mathrm{p}$. The model yielding the smallest AIC fits the data best.

\section{RESULTS AND DISCUSSION}

Means, standard deviation (SD) and coefficients of variation $(\mathrm{CV} \%)$ for $\mathrm{BW}$ and $\mathrm{WW}$ of Friesian calves are given in table (2). Means of BW and WW were $30.4 \mathrm{Kg}$, and $85.1 \mathrm{Kg}$, respectively. These estimates were higher than those of Frisian cows in Egypt as reported by Safaa and Gharib (2017)for BW while were less than for the WW in the same study. They found that means of BW and WW were 28.6 kgand92.6kg, respectively, while, means of BW and WW were lower than those obtained by Atil et al.(2005)BW(31.8kg) and WW (97.4kg) on Friesian cattle. The present estimates of BW and WW were similar to those observed by Hwang et al.(2008) on Friesian cows in Egypt. 
Table 2. Means, standard deviation (SD) and coefficients of variation (CV\%) for growth traits of Friesian calves

\begin{tabular}{lcccc}
\hline Traits & No. of records & Mean & SD & CV\% \\
\hline BW & 1371 & 30.4 & 3.8 & 12.4 \\
WW & 678 & 85.1 & 9.9 & 11.6 \\
\hline
\end{tabular}

The coefficients of variation (CV \%) for BW and WW in the present study were $12.4 \%$ and 11.6 , $\%$ respectively. Safaa and Gharib (2017) found that CV \% for BW and WW were $11.1 \%$ and $12.1 \%$, respectively. Also, Hwang et al. (2008) found that, estimates (CV\%)for BW and WW were 15.3 and 22.0 respectively. Differences between estimates of this study and the previous research may be due to the assumed differences in methods of statistical analysis, the number of used records or due to different farm management.

\section{Non genetic parameters:}

The number of lactations and season of calving had highly significant $(\mathrm{P}<0.001)$ effect on $\mathrm{BW}$ and WW (Table 3). Similar results were obtained byAbdel-Glil and El-Banna(2001). It seems likely that improved conditions of dams in winter season of calving refers to the confound effects of moderate climate and availability of green forages under the Egyptian conditions.

Abdel-Glil and El-Banna (2001)concluded that winter and spring had the highest means for WW than the other seasons. On the other hand, Amr (2013) and Faid-Allah (2015)noticed that spring had the highest means for calf BW than the other seasons.

Year of calving had highly significant $(\mathrm{P}<0.001)$ effect on BW and WW as shown in table (3). The differences in BW and WW from year to year of calving may be due to variation in management practices, change in herd size from year to another.

Body weights of calves in the first parity were the least when compared with other parities. Weaning weights were increasing with advancement of parity and almost reached its maximum at the $5^{\text {th }}$ parity then decreased thereafter (Table 3). Similar result were reported by Abdel-Glil and El-Banna (2001)who found gradual increase in average birth weight in both male and female calves from the first to the fourth parity followed by a decrease in that weight thereafter.

Interaction between year of calving and season of calving hade highly significant $(\mathrm{P}<0.001)$ effect on $\mathrm{BW}$ and WW.

\section{Genetic parameters:}

Direct heritability $\left(\mathbf{h}^{2}\right)$ estimates were moderate. They ranged from 0.28 to 0.30 for $\mathrm{BW}$ and from 0.18 to 0.28 for WW (table 4). In general, there was a decrease in the estimate of heritability for BW and differences in $\mathrm{h}^{2}{ }_{\mathrm{a}}$ estimates among various studies for the same traits of the same breed which may be due to differences in the number of records used.

Estimates of heritability from the animal model were comparable to those reported by Meyer et al. (1993), Kootset al. (1994), Bennett and Gregory
(1996), Eriksson et al. (2004), Sadek et al. (2005), Atil et al.(2005) and El-Saied et al. (2006) in Friesian cows. Differences between the results of this study and the results of previous research may be due to differences in the methods of statistical analysis, the number of records used or to different management and ways of care.

Maternal heritability's $\left(\mathrm{h}_{\mathrm{m}}^{2}\right)$ were higher for BW (0.06 to 0.08$)$ than that for WW (0.04), indicating the importance of the maternal effect on birth and weaning weights. Atil et al.(2005)observed that maternal heritability were estimates for the same traits, being 0.14 and 0.06 , respectively. A lower maternal heritability estimate $(0.02)$ was found in the work of Montaldo and Kinghorn (2003) for a multi breed population of beef cattle.

Stamer et al. (2004) found that, direct heritabilities were 0.63 for birth weight, and 0.50 for weaning weight. Maternal heritabilities were 0.07 and 0.02 , respectively. Also Coffey et al. (2006) found that, direct heritability estimates were 0.53 for birth weight, and 0.45 for weaning weight.

Estimates of Permanent environmental effect $\mathrm{Pe}^{2}$ ranged from $0.003(\mathrm{WW})$ to $0.08(\mathrm{BW})$ across the tested models, being the highest $(0.08)$ in the $2^{\text {nd }}$ model. Permanent environmental effect $\left(\mathrm{Pe}^{2}\right)$ in the $2^{\text {nd }}$ model was relatively higher, while inclusion of maternal genetic effects (Model 3-6) showed further reduction in $\mathrm{h}^{2} \mathrm{a}$ for which there is negligible difference in $\mathrm{h}^{2} \mathrm{a}$ of the other models within each trait (table 4).

\section{Ranking the Models:}

The six models of the current study were compared. The likelihood function showed that the full animal model best fit the data. Narrow differences in AIC values were observed. The models of the study were arranged according to the AIC values to arrive at the best model for each attribute after the AIC ranking. It was observed that Model 5 was best for BW while Model 4 was the best for WW trait, Models (4\&5) were sufficient to explain the variation in the data. It is notable that data structure has a great impact on the accuracy of maternal effects estimation. The best model is different between the two traits. This may be due to the difference in number for the two traits or for care and farm management reasons. Gad (2014) and Jhony et al. (2017) indicated that Akaike Information Criterion (AIC) was used to determine equation which model shows the best performance of the studied traits. 
Table 3. Least square means (LSM) and standard Error (SE) for factors affecting growth traits in Friesian Calves.

\begin{tabular}{|c|c|c|c|c|}
\hline 2 & No. & BW & No. & WW \\
\hline \multicolumn{5}{|l|}{ Parity } \\
\hline 1 & 400 & $29.7 \pm 0.39$ & 176 & $81.7 \pm 1.38$ \\
\hline 2 & 287 & $31.4 \pm 0.39$ & 137 & $85.3 \pm 1.41$ \\
\hline 3 & 202 & $32.2 \pm 0.43$ & 100 & $85.6 \pm 1.54$ \\
\hline 4 & 145 & $32.8 \pm 0.46$ & 83 & $87.1 \pm 1.65$ \\
\hline 5 & 113 & $32.6 \pm 0.50$ & 53 & $87.8 \pm 1.85$ \\
\hline 6 & 79 & $33.1 \pm 0.61$ & 38 & $83.7 \pm 2.03$ \\
\hline 7 & 58 & $32.3 \pm 0.61$ & 31 & $85.5 \pm 2.17$ \\
\hline 8 & 106 & $32.3 \pm 0.49$ & 60 & $84.4 \pm 1.75$ \\
\hline Sig. & & $* * *$ & & * \\
\hline \multicolumn{5}{|l|}{ Season } \\
\hline Autumn & 360 & $32.1 \pm 0.40$ & 194 & $87.8 \pm 1.40$ \\
\hline Winter & 457 & $32.3 \pm 0.38$ & 204 & $85.3 \pm 1.34$ \\
\hline Spring & 350 & $33.0 \pm 0.38$ & 160 & $83.4 \pm 1.39$ \\
\hline Summer & 223 & $31.4 \pm 0.43$ & 120 & $84.1 \pm 1.49$ \\
\hline Sig. & & $* * *$ & & $* *$ \\
\hline \multicolumn{5}{|l|}{ Year } \\
\hline 1990 & 259 & $29.1 \pm 0.77$ & 29 & $80.63 \pm 4.89$ \\
\hline 1991 & 30 & $29.1 \pm 1.08$ & - & - \\
\hline 1992 & 52 & $28.2 \pm 0.93$ & - & - \\
\hline 1993 & 51 & $25.4 \pm 1.03$ & 16 & $81.6 \pm 7.29$ \\
\hline 1994 & 52 & $25.9 \pm 1.04$ & 51 & $87.08 \pm 6.96$ \\
\hline 1995 & 50 & $26.1 \pm 1.07$ & 43 & $88.93 \pm 6.97$ \\
\hline 1996 & 63 & $28.3 \pm 1.05$ & 51 & $82.95 \pm 6.77$ \\
\hline 1997 & 246 & $29.9 \pm 0.89$ & 106 & $94.9 \pm 6.17$ \\
\hline 2000 & 67 & $31.7 \pm 0.98$ & & \\
\hline 2001 & 82 & $32.3 \pm 0.88$ & 31 & $87.3 \pm 3.98$ \\
\hline 2002 & 28 & $33.8 \pm 1.15$ & 24 & $93.9 \pm 4.11$ \\
\hline 2003 & 52 & $35.9 \pm 0.93$ & 45 & $92.1 \pm 3.76$ \\
\hline 2004 & 61 & $36.06 \pm 0.97$ & 50 & $92.3 \pm 3.87$ \\
\hline 2005 & 59 & $34.9 \pm 0.96$ & 41 & $85.6 \pm 3.9$ \\
\hline 2006 & 30 & $34.9 \pm 1.05$ & 23 & $86.9 \pm 4.16$ \\
\hline 2007 & 46 & $34.9 \pm 1.06$ & 39 & $78.9 \pm 4.16$ \\
\hline 2008 & 43 & $35.05 \pm 1.06$ & 40 & $87.1 \pm 4.14$ \\
\hline 2009 & 25 & $35.9 \pm 1.25$ & 19 & $86.8 \pm 4.77$ \\
\hline 2010 & 27 & $36.9 \pm 1.33$ & 17 & $78.9 \pm 5.30$ \\
\hline 2011 & 31 & $36.8 \pm 1.23$ & 26 & $78.9 \pm 4.96$ \\
\hline 2012 & 23 & $31.7 \pm 1.63$ & 15 & $73.6 \pm 6.24$ \\
\hline 2013 & 13 & $34.9 \pm 1.55$ & 12 & $79.3 \pm 6.09$ \\
\hline Sig. & & $* * *$ & & $* * *$ \\
\hline \multicolumn{5}{|l|}{ Sex } \\
\hline 1 & 687 & $32.9 \pm 0.37$ & 333 & $86.5 \pm 1.28$ \\
\hline 2 & 703 & $31.5 \pm 0.36$ & 345 & $83.8 \pm 1.22$ \\
\hline Sig. & & $* * *$ & & $* * *$ \\
\hline
\end{tabular}


Table 4. Estimates of covariance components and direct $\left(h^{2} d \pm S E\right)$ and maternal heritability $\left(h^{2}{ }_{m} \pm \mathrm{SE}\right)$ as well as direct $\left(e^{2} \pm S E\right)$, maternal permanent variances $\left(c^{2} \pm S E\right)$

\begin{tabular}{|c|c|c|c|c|c|c|c|c|c|c|c|c|}
\hline \multicolumn{9}{|c|}{ Covariance components } & \multicolumn{4}{|l|}{ Heritability } \\
\hline Model & $\begin{array}{c}\text { Traits } \\
\text { BW }\end{array}$ & $\begin{array}{c}\sigma_{\mathrm{a}}^{2} \\
4.64\end{array}$ & $\sigma_{m}^{2}$ & $\sigma_{\mathrm{am}}^{2}$ & $\sigma^{2} P_{e}$ & $\begin{array}{c}\sigma_{\mathrm{e}}^{2} \\
10.73\end{array}$ & $\begin{array}{c}\sigma_{p}^{2} \\
15.36\end{array}$ & $\begin{array}{c}\mathrm{h}_{\mathrm{a}}^{2} \\
0.30 \pm 0.09\end{array}$ & $\mathrm{~h}_{\mathrm{m}}$ & $\mathrm{R}_{\mathrm{am}}$ & $\mathrm{P}_{\mathrm{e} 2}$ & $\begin{array}{c}\mathrm{e}^{2} \\
70 \pm 0.9\end{array}$ \\
\hline Model1 & WW & 29.57 & & & & 73.66 & 103.24 & $0.29 \pm 0.18$ & & & & $0.71 \pm 0.17$ \\
\hline \multirow{2}{*}{ Model2 } & BW & 4.12 & & & 1.22 & 9.30 & 14.64 & $0.28 \pm 0.09$ & & & $0.083 \pm 0.11$ & $0.64 \pm 0.14$ \\
\hline & WW & 25.73 & & & 0.26 & 74.78 & 100.77 & $0.26 \pm 0.17$ & & & $0.003 \pm 0.20$ & $0.74 \pm 0.26$ \\
\hline \multirow[b]{2}{*}{ Model3 } & BW & 4.0 & 1.2 & 0.0 & & 10.0 & 15.2 & $0.26 \pm 0.09$ & $0.08 \pm 0.03$ & 0.0 & & $0.66 \pm 0.09$ \\
\hline & WW & 22.0 & 4.0 & 0.0 & & 80.0 & 106.0 & $0.21 \pm 0.16$ & $0.04 \pm 0.04$ & 0.0 & & $0.75 \pm 0.16$ \\
\hline \multirow{2}{*}{ Model4 } & BW & 4.0 & 1.0 & 1.0 & & 10.0 & 16.0 & $0.25 \pm 0.09$ & $0.06 \pm 0.04$ & $0.50 \pm 0.54$ & & $0.63 \pm 0.38$ \\
\hline & WW & 22.0 & 4.0 & 2.4 & & 80.0 & 108.4 & $0.20 \pm 0.18$ & $0.04 \pm 0.08$ & $0.26 \pm 1.8$ & & $0.74 \pm 0.16$ \\
\hline \multirow{2}{*}{ Model5 } & BW & 3.6 & 0.90 & 0.0 & 0.50 & 10.0 & 15.0 & $0.24 \pm 0.09$ & $0.06 \pm 0.03$ & 0.0 & $0.03 \pm 0.12$ & $0.67 \pm 0.14$ \\
\hline & WW & 19.35 & 4.3 & 0.0 & 3.22 & 73.8 & 100.67 & $0.19 \pm 0.15$ & $0.04 \pm 0.04$ & 0.0 & $0.03 \pm 0.21$ & $0.37 \pm 0.26$ \\
\hline \multirow{2}{*}{ Model6 } & BW & 3.6 & 1 & 1.0 & 0.60 & 10.0 & 16.2 & $0.22 \pm 0.81$ & $0.06 \pm 0.04$ & $0.53 \pm 0.58$ & $0.03 \pm 0.11$ & $0.62 \pm 0.13$ \\
\hline & WW & 19.08 & 4.24 & 4.2 & 3.18 & 73.80 & 104.54 & $0.18 \pm 0.16$ & $0.04 \pm 0.08$ & $0.47 \pm 01.0$ & $0.04 \pm 0.20$ & $0.71 \pm 0.25$ \\
\hline
\end{tabular}

$\sigma^{2}{ }_{a}$-additive direct genetic variance $; \sigma^{2}$-additive maternal genetic variance; $\sigma^{2}$ am $=$ genetic covariance between direct and maternal effect, $\sigma_{p e}^{2}$-permanent environmental maternal variance ; $\sigma_{\mathrm{p}}^{2}$-phenotypic variance-sum of variance and covariance components; $\mathrm{h}_{\mathrm{a}}^{2}$-direct heritability; $\mathrm{h}_{\mathrm{m}}^{2}$-maternal heritability.; $\mathrm{R}_{\mathrm{am}}=$ direct -maternal genetic correlation; $\sigma^{2}{ }_{\mathrm{e}}$-error variance .

Table 5.Akaika information criteria (AIC) ranking of animal models

\begin{tabular}{ccccc}
\hline & \multicolumn{2}{c}{ BW } & \multicolumn{2}{c}{ WW } \\
\hline Model & $-2 \log$ & AIC & $-2 \log$ & AIC \\
\hline 1 & 5126.7 & 5128.7 & 3764.11 & 3766.1 \\
2 & 5124.11 & 5128.1 & 3746.0 & 3750.0 \\
3 & 5118.1 & 5122.1 & 3743.6 & 3747.6 \\
4 & 5121.7 & 5125.7 & 3743.4 & 3747.4 \\
5 & 5116.4 & 5122.4 & 3743.2 & 3749.2 \\
6 & 5119.8 & 5125.8 & 3742.5 & 3748.5 \\
\hline
\end{tabular}

$\mathrm{AIC}=-2(\log . \mathrm{L})+2 \mathrm{P}$.

Estimates of breeding values (EBV) ofthe studied traits are shown in Table 6 and 7. On the basis of the selected model for each traits, using Model 5 for BW and Model 4 for WW, where these models $(4,5)$ were used to estimate EBV. The ranges of breeding value for sires(SBV) were $5.6 \mathrm{~kg}$ and $9.39 \mathrm{~kg}$ for BW and WW respectively; where the sire represents great importance in the inheritance of future generations, while they were $6.8 \mathrm{~kg}$ and $10.6 \mathrm{~kg}$ for dam breeding value (DBV) for BW and WW, respectively. Calves breeding values $(\mathrm{CBV})$ were in the range $7.4 \mathrm{~kg}$ and 13.9 kgfor $\mathrm{BW}$ and $\mathrm{WW}$, respectively. The higher range of calves breeding values compared with that of sire or dams means that selection for BW for calves lead to an increase in WW for the next generation. On the other hand, the accuracy of (SBV) for both traits was relatively greater $(65 \%$ and $58 \%)$ than that of DBV (47\%to $54 \%)$ or $\mathrm{CBV}(0.56 \%$ to $0.50 \%$ ).Stamer et al. (2004)observed that, breeding values estimate show clear differences between sires combined with high reliabilities. Different rankings of sire breeding values for both traits allow selecting sires with both average and low birth weights and high daily gains. These findings indicate the vital role of sire effect on BW and WW which might be due to the large number of daughters per sire. The same trends were observed by Atil et al.(2005) and Safaa and Gharib (2017). 
Table6. Minimum, maximum, range and accuracy of predicted breeding values of estimated breeding values for $\mathbf{B W}$

\begin{tabular}{rccccccc}
\hline & Minimum & S.E & Accuracy & Maximum & S.E & Accuracy & Range \\
\hline Sire & -2.416 & 1.08 & 0.84 & 3.196 & 1.52 & 0.65 & 5.61 \\
Dam & -1.636 & 1.73 & 0.50 & 5.161 & 1.76 & 0.47 & 6.79 \\
Calves & -3.955 & 1.58 & 0.61 & 3.483 & 1.66 & 0.56 & 7.44 \\
\hline
\end{tabular}

S.E $=$ Standard error; Min. $=$ minimum; Max. $=$ maximum, Range $=$ Maximum minus Minimum and Range $(\mathrm{BW}$ Max- $\mathrm{BW}$ Min $)$

Table7. Minimum, maximum, rangeand accuracy of predicted breeding values of estimated breeding values for $\mathbf{W W}$

\begin{tabular}{cccccccc}
\hline & Minimum & S.E & Accuracy & Maximum & S.E & Accuracy & Range \\
\hline Sire & -4.342 & 4.26 & 0.42 & 5.045 & 3.83 & 0.58 & 9.39 \\
Dam & -5.565 & 4.44 & 0.52 & 5.01 & 3.96 & 0.54 & 10.58 \\
Calves & -7.512 & 3.96 & 0.54 & 6.404 & 4.06 & 0.50 & 13.92 \\
\hline
\end{tabular}

S.E $=$ Standard error; Min. $=$ minimum; Max. $=$ maximum, Range $=$ Maximum minus Minimum and Range $(\mathrm{BW}$ Max- $\mathrm{BW}$ Min $)$

As shown in the next figure, the genetic trend expressed by animal breeding value for birth weight and weaning weight revealed almost parallel trend for both traits except those estimates of the year's $3,4,5$ and 6 . However, the genetic trend of breeding values fluctuated across years of the study. This indicates changes in genetic values. Similar results were obtained by Plasse et al. (2002), Hossen et al. (2012) and Safaa and Gharib (2017). of particular importance is effect of year of birth which could be related to better nutritional and climatic environments mainly due to the difference the direct effect on the availability and quality of nutrients.

In general, year of calving is considered the most important source of variation in different weights at per weaning period and this may be attributed to changes in genetic values.

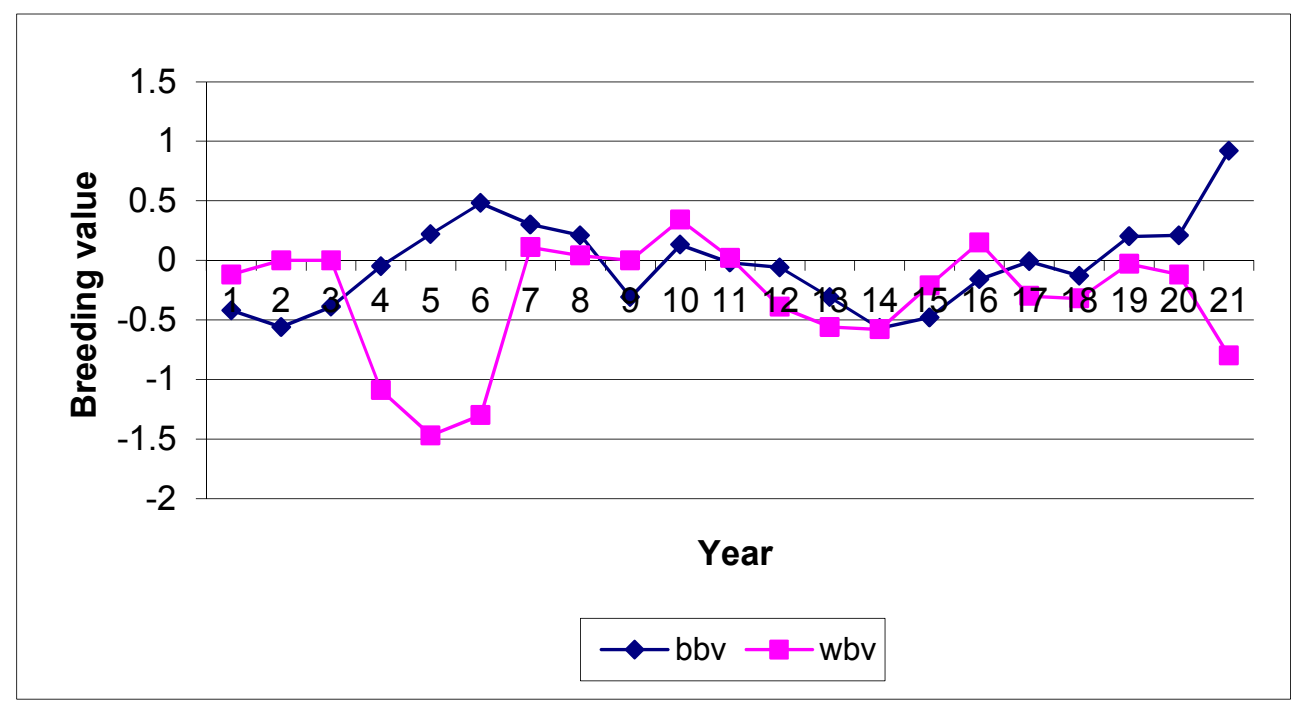

Figure 1. Genetic trend of estimated values for birth weight (bbv) and weaning weight (wbv) as regressed against year

\section{CONCLUSION}

The differences in BW and WW from year to year of calving may be due to variation in management practices including changes in weather and feeding practices, change in herd size from year to another. Thus, year of calving is considered as the most important source of variation in different weights at calf weaning. This fact was evidenced by fluctuated genetic trend of breeding values across years of the study denoting variable level of management among years of production.
Among six models tested using Akaike Information Criterion (AIC) to determine the most appropriate model for the studied traits, Model 5: $\mathrm{Y}=\mathrm{Xb}+\mathrm{Z}_{1} \mathrm{a}+\mathrm{Z}_{2} \mathrm{c}+\mathrm{Z}_{3} \mathrm{~m}+\mathrm{e}, \operatorname{Cov}(\mathrm{a}, \mathrm{m})=0 \mathrm{~A} \sigma_{\mathrm{am}}$ was the most appropriate model for BW, while, Model 4: $\mathrm{Y}=\mathrm{Xb}+\mathrm{Z}_{1} \mathrm{a}+\mathrm{Z}_{3} \mathrm{~m}+\mathrm{e}, \operatorname{Cov}(\mathrm{a}, \mathrm{m})=\mathrm{A} \sigma_{\mathrm{a}, \mathrm{m}} \mathrm{Was}$ the most appropriate model for WW trait, to represent BW and WW of claves of the used data.

The higher range of calves breeding values compared with that of sires or dam's means that selection for BW of calves may lead to higher WW for the next generation; in addition to selection the 
parents in high production in beef cattle. On the other hand, the accuracy of (SBV) for both traits was relatively greater than that of $\mathrm{DBV}$ or $\mathrm{CBV}$. This finding indicated the vital role of sire effect on $\mathrm{BW}$ and $\mathrm{WW}$; these might be due to the large number of daughters per sire.

The study recommends using model 5 when evaluating BW of the herd of and the use of model 4 for evaluation of WW trait; with an estimate of the EBV of the herd based onthe best model for each trait.

\section{REFERENCES}

Abdel-Galil, M.F. and M.K. Elbanna, 2001. Genetic and non-genetic analysis for body weight traits of calves in a herd of Friesian cattle in Egypt. Minufiya.J. Agric. Res., 26 (1): 99.

Akaike, 1973. Information Theory and an Extension of the Maximum Likelihood principle in $2^{\text {nd }}$ International symposium on information Theory (B.N.Petrov and F. Csaki,eds.). AkademiaiKiado, Budapest.

Allam, A.A.F., 2011. Evaluation of productive and reproductive performance of Friesian cattle under Egyptian condition. M.Sc. Thesis, Fac. of Agric. Damanhur Univ. Egypt.

Amr. M.A., 2013. Evaluation of performance of some dairy herds in Egypt $\mathrm{PhD}$.Thesis Fac.Agaric . Alexandria Universe . Egypt

Assan, V., A. Masache and G. Tambe, 2011. Impact of maternal effects on ranking of animal Models in genetic parameter estimation for 18-Months weight in indigenous cattle of Zimbabwe volume1,IJPAESIssue . 2231-4490.

Atil, H., A. S. Khattab and L. Badawy, 2005. Genetic parameter of birth and weaning weights for Friesian calves by using an animal model. Arch. Tierz., Dummerstorf 48 (3), 261-269.

Aynalem H., 2006. Genetic and Economic Analysis of Ethiopian Boron Cattle and their Crosses with Holstein Friesian in Central Ethiopia. A Ph.D. Thesis division of dairy cattle breeding National dairy research institute, Karnal-132001 (Haryana), India.pp.65-146.

Bennett, G.I. and K. E. Gregory, 1996. Genetic(co)variances among birth weight, 200day weight, andpostweaning gain in composites and parental breeds ofbeef cattle. J. Anim. Sci74, 2598-2611.

Boldman, K.G., L.A. Kriese, L.D. Van Vleck, C.P. Van Tassell, and S.D. Kachman, 1995.A manual for the use of MTDFREML.ARS, USDA, Clay Center, N.E.,

Coffey, MP; J. Hickey and S;T.I., Brother stone, 2006. Genetic aspects of growth of HolsteinFriesian dairy cows from birth to maturity.SO Journal of Dairy Science Vol.(89) 322- 329.JAN (2006).

El-Saied1, L.F. de la R., Fuente, Rodriguez and F.,San Primitive., 2006. Genetic parameter estimates for birth and weaning weights, pre- weaning daily weight gain and three type traits for Charolaise beef cattle in Spain Spanish J. of Agri. Research 4(2), 146-155.

Eriksson s., A. Nasholm, K., Johansson and J. Philipson, 2004. Genetic parameters for calving difficulty, stillbirth, and birth weight for Hereford and Charolaise at first and later parities. J Anima.Sci. 82, 375-383.

Faid-Allah, E., 2015. Genetic and Non-Genetic Analysis for Milk Production and Reproductive Traits in Holstein Cattle in Egypt.(JITV) J.Ilmuternaak and veterinary Vol. 20, No.1 : 1017.

Gad, S.M.A., 2014. Genetic parameters for direct and maternal effects on different Growth rates inBarki Lambs Egyptian J.Anim.Prod. 51(3): 172-177.

Hossen, M.S, S.S. Hossain, M. A. Hoque and M.R. Amin, 2012. Genetic trends of some important dairy traits of crossbred cows at Baghabarighat milk shed area in Bangladesh. Bang. J. Anim. Sci. 41 (2):67-73.

Hwang, J.M. H.C. Choi,, Y.H. Kim,, S.K.M. Choy, C. Lee and J.B, Kim, 2008. Genetic relationship of gestation length with birth and weaning weight in Han woo(Boss Taurus Coronae)AsianAust.J.Anim.Sci.Vol.21,No.5:633-639.

Jhony,T.T., C. Alessandro and S.R. Gandweber, 2017. Comparing non-linear mathematical models to describe growth of different animals. Maringa,Vol.39,n.1,p.73-81.

Koots, K. R., J. P. Gibson, C. Smith, and W. Wilton, 1994. Analyses of published parameter estimates for beef production traits. 1. Heritability. Anim. BreedingAbst. 62:309-338.

Martínez. R.A, R. Dassonneville, D. Bejarano. , Jimenez.A, G. Even., G. Mészáros, J. Sölkner, 2016. Direct and maternal genetic effects on growth, reproduction, and ultrasound traits in zebu Brahman cattle in Colombia. J. Anim Sci. 94(7):2761-9. Doi: 10.2527/Jas. -0453.

Meyer, K., 1993. Estimates of direct and maternal correlations among growth traits in

Australian beef cattle Lives.Prod. Sci. 8:121-13.

Montaldo H.H., B.P. Kinghorn, 2003. Additive and non-additive, direct and maternal genetic effects for growth traits in a multibreed population of beef cattle. Arch Med Vet 35(2), 243-248.

Plasse D.O, H. Verd, R. Fossi, R. Romero, P. Hoogesteijn and J. Bastardo, 2002. (Co)variance components, genetic parameters and annual trends for calf weights in a pedigree Brahman herd under selection for three decades. J. Anim. Breed. Genet. 119: 141 - 153.

Sadek, M.H., A.R. Shemeis, and N.A. Shalaby, 2005. Different models for estimating genetic parameters for growth traits of Holstein Friesian under semitropical conditions Egyptian j. anim. prod., 42(1):11-18

Safaa. S.S and M.G. Gharib, 2017. Estimation of Genetic and Phenotypic Parameters for Growth Traits of Friesian Cattle Raised in Egypt. J. 
Animal and Poultry Prod.., Mansoura Univ., Vol. 8 (7): 187 - 193, 2017.

SAS, 2003. User's guide: Statistics, version 9. 4th Ed. SAS Ins., Inc., Cary., NC, USA.

Stamer, E; S. Hafez, W. Junge, E. Kalm, 2004.

Genetic parameters of birth weight and weaning weight for Holstein female calves. ZUCHTUNGSKUNDE, Vol. (76),:188-

\title{
تقدير المعالم الوراثية لصفات النمو باستخدام نماذج إحصائية مختلفة لأبقار الفريزيان المرباه في مصر صفاء صلاح سند ، محمود غريب
}

\author{
معه بحوث الانتاج الحيوانسي ، مركز البحوث الزراعية ، وزارة الزراعة ، الدقي ، مصر.
}

تهدف هذه الدر اسة الى تقدير المعالم الور اثية لصفات النمو في ماثية الفريزيان المربأة في مصر باستخدام نماذج متعددة حيث أجريت الدراسة

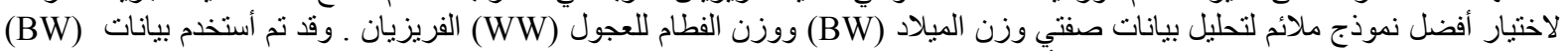

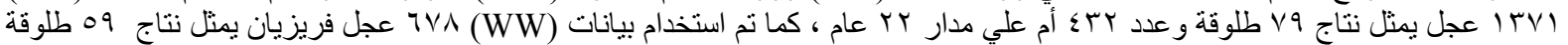

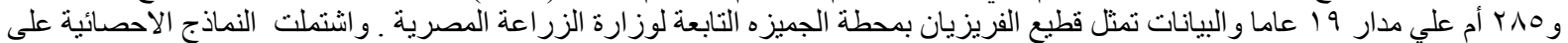

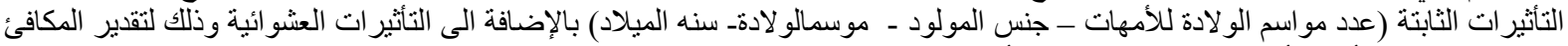

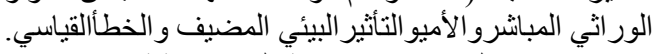

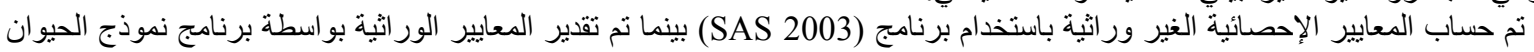

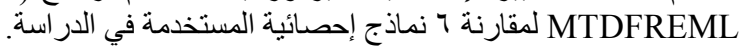

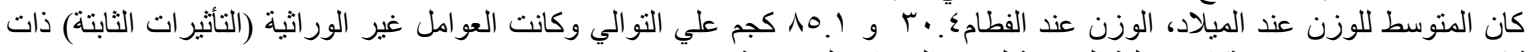

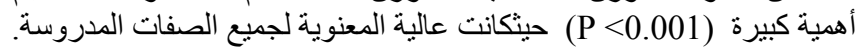

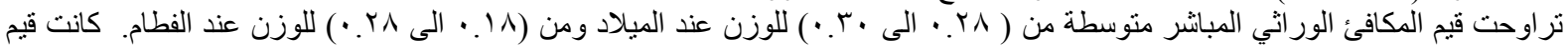

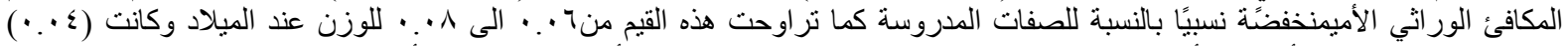

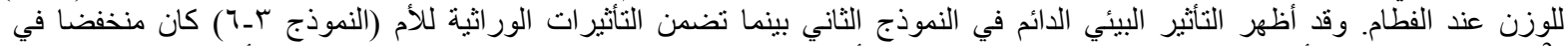

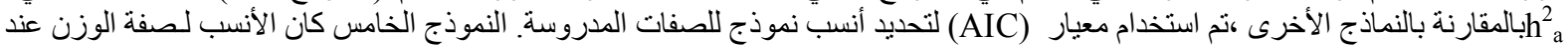
$Y=X b+Z_{1} a+Z_{2} c+Z_{3} m+e, \operatorname{Cov}(a, m)=0$ A $\sigma_{\text {am }}$

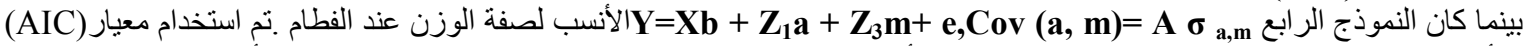

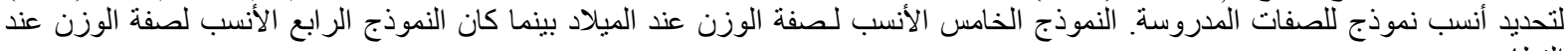

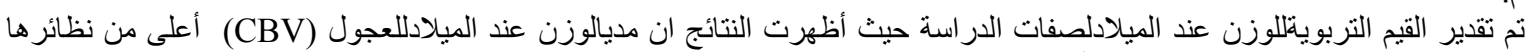
الفطام. للآباء و الامهات و هذا يعني ان الانتخاب علي أساس الوزن عند الميلاد للعجول يؤدي إلى زيادة صفه الوزن الني عند عند الفطام للجيل القادم. 